\title{
ASSESSMENT OF AVAILABILITY OF WOOD RESOURCES USING GEOGRAPHIC INFORMATION AND ANALYTICAL SYSTEMS (THE KRASNOYARSK TERRITORY AS A CASE STUDY)
}

\author{
Aleksandr Petrovich Mokhirev*, Marija Olegovna Pozdnyakova, Sergej Olegovich Medvedev, \\ Vladimir Olimbaevich Mammatov \\ Lesosibirsk Branch of Reshetnev Siberian State University of Science and Technology, Lesosibirsk, Russia
}

The article analyzes the availability of wood resources as a key indicator of the sustainability of logging operations. This study leads to the conclusion that the process of assessing the availability of wood resources is associated with the collection and analysis of a large amount of data. At the same time, the more raw data is analyzed, the better the evaluation is. This article describes the experience of creating a software product based on geographic information and analytical systems designed for detailed assessment of the entire set of factors that determine the level of availability of forest resources. The results of the assessment of the availability of wood resources in the Krasnoyarsk Territory are presented. The results obtained will allow to increase the efficiency of the use of forest resources, to select the ideal technology and system of machines, to avoid environmental disturbance, to develop the optimal route for timber transportation which will eventually allow the forest user to make the largest profit from the timber products received.

Key words: Availability of wood resources, Profitability, Logging, Geographical information and analytical systems, Transport availability of wood resource

\section{INTRODUCTION}

Currently, the industrial development of forest resources in Russia faces significant difficulties. About half of Russia's forest resources are protected from logging on organizational and legal grounds, and the remainder is extremely heterogeneous and the economic conditions for its use are very different.

The division of forests according to the economic criterion is possible using the notion of "economic availability of wood resources".

This term is increasingly found in the research of modern scientists. A.G. Tretyakov [1] believes that economic availability cannot be considered separately from environmental availability R.V. Polshshvedkin and A.N. Mariev [2] propose to move away from costed assessment of wood and determine the economic availability of wood resources in the relative size (classes). At the same time among scientists there is no unequivocal definition of this notion. The availability of wood resources is a broad term that includes many indicators. However, in the final analysis, it characterizes the viability of the forest industry. Viable forest industry, in the first place, is characterized by high profitability, ensuring the competitiveness of timber products on the market.

Therefore, timely and accurate assessment of the availability of wood resources is a key moment in creating an efficient and stable timber industry complex. In order for the forestry industry to actively develop, it is necessary to use all available resources (not only raw materials, but also labor and economic resources). This requires to have full information about the territory used, such as: forest resource base, human resources, the availability and development of infrastructure (including road network), relief features, climatic indicators, etc.

Thus, the possibility of obtaining an accurate assessment of the availability of forest resources is closely related to the large amount of data. This data should be systematized, updated and promptly processed.

\section{THEORY AND EXPERIMENTS}

To date, the term "availability of wood resources" does not have a single definition. The authors distinguish several types of availability of wood.

1. The ecological availability of wood resources is expressed in limiting their use, as this can disrupt natural processes, undermine the ability of this resource to perform ecological functions, and reduce its ecological value. In some works $[3,4,5]$ such forests are considered to be unavailable and forbidden to cutting by law. Mathematically, this can be expressed by formula 1 .

$W_{\text {ea }} \notin W_{f h}$

where $W_{\text {ea }}$ - environmentally available wood; $W_{\text {fh }}$ - wood forbidden to cutting.

2. The technological availability of wood is an indicator that characterizes certain wood resources that can be used with a certain technology at a certain point of time. This type of availability is formed for each type of harvested wood products. For example, the technology for cutting sawlogs makes the production of wood chips unavailable. 
3. The technical availability of wood is an indicator characterizing wood resources that can be used by a certain technique at a certain point of time. For certain natural and industrial conditions, a forestry machines with certain characteristics should be used. Thus, the technical availability of wood will be positive under the following conditions (formula 2):

$$
T A=\left\{\begin{array}{l}
i_{\max } \geq i_{\text {grad }} ; \\
\delta_{\text {pressure }}<\delta_{\text {terrain }} \\
d_{p . t .} \geq d_{\max } ; \\
\mathrm{t}_{\max } \geq T_{\max } ; \\
\mathrm{t}_{\min } \leq T_{\min } .
\end{array}\right.
$$

Where $i_{\max }$ - maximum working gradient of the machine; $i_{\text {grad }}$ - maximum terrain gradient;

$\delta_{\text {pressure }}$ - specific ground pressure;

$d_{p . t .}$ - terrain load capacity;

$d_{\max }$ - maximum diameter of trees processed by the working body;

$d$ - maximum diameter of trees;

$t_{\min }, t_{\max }$ - operating temperature range of the machine;

$T_{\text {min }}, T_{\text {max }}$ - ambient temperature range.

4. The transport availability of wood is an opportunity to transport wood to the delivery point by certain technical means at a certain time. It should be noted that wood resources can become transport available by changing the means of transporting timber or improving transport routes $[6,7]$. This type of availability is closely related to technological and technical availability.

5. The economic availability of wood resources. This is a geographical location of the forest in relation to points of sale, which, with the current organizational and technical level of production, will provide the necessary level of profitability. Determination of economic availability of resources is achieved by measuring economic indicators such as the price of reproduction and its full cost price, including logging and transportation to the consumer. This type of availability is most often considered in various studies. At the same time, scientists offer different interpretations to the term "economic availability". To some extent, transport, technological and technical availability can be applied to economic availability, as today, with certain investments, it is possible to change the forestry equipment and technology of logging, create a transport infrastructure, etc. And this will change the transport, technological and technical availability of the resource. Mathematically, economic availability is expressed by formula 3 :

$E A=I-C l-C t-C i-R$,

Where EA - economic availability of wood resources;
$I$ - income from the sale of logging products;

$\mathrm{Cl}$ - logging costs;

Ct - transportation costs of forest resources;

$\mathrm{Ci}$ - costs for the creation and maintenance of the necessary transport infrastructure;

$R$ - rate of production profitability.

Based on the above definitions, it is possible to formulate a general definition for the term "availability of wood resources": Availability of wood resources is the opportunity of ecologically safe and economically efficient cutting of a certain type of wood products using certain forestry machinery and technology.

In order to obtain an objective assessment of the availability of forest resources of a country, region or individual forest plot, all significant factors should be taken into account. These are the factors, the change of which greatly influences on the level change of availability of wood [8]. These include:

- Profit from logging production (from the use of forest resources). All objective costs that the producer bears in the process of logging operations will eventually be included in the cost of final products. At the same time, it does not matter what the final product is saw logs or timber.

- Transport availability of forest land. When transporting timber, several types of transport are used: water, rail and road. Each of them differs in cost and related factors of use.

- Cost of forestry work. Each tenant of a forest site is obliged to do quite costly reforestation activities in a certain amount at a certain time (depending on the regional policy and the type of forest plots).

Enterprises need access to structured information on the status and characteristics of forest areas (such as distance from industrial sites, possible ways of transporting wood to processing sites, tree species in the plot, the relief of the site, the transport routes on the site, the soil composition of the site, information on protective and nonoperational forests, etc.).

The most complete idea of the availability of forest on the area, its number, quality and location, can be obtained on the basis of the geographic approach. The most effective way to have all the necessary information and provide it in an available form to the enduser is the development of a specialized geographic information and analytical system (GIAS) for forest users [9].

The process of collecting and updating geographic information requires the use of material, technical and organizational resources.

However, using the readymade GIAS, the forest industry enterprise will be able to analyze the forest area of interest in a shorter time and with less cost, view the volume of the possible logging ("the allowable cut"), the places where timber is banned, the shortest and most economical transportation routes of wood to the places of its pro- 
cessing, the seasonality of wood transporting from the logging area, to plan the development of logging areas, to determine the direction of cutting, define convenient location of loading and storage [10].

Thus, to date, there are some conditions for creating a geographic information resource necessary for preliminary assessment of the availability of forest resources, planning and modeling of industrial activities of forest industry enterprises.

The creating and updating of cartographic materials is an urgent issue and is one of the most important in ensuring effective management of forest resources. The specialized GIAS for forest users should contain the following elements:

- information on wood growing stock located on the territory of the forestry area (divided into stocks of coniferous and deciduous species);

- information on existing and projected transport routes suitable for wood transportation;

- information on water bodies (DTM, maps);

- information on forest use (tenants of forest sites);

- information about the terrain (DTM, maps);

- boundaries of the territory under analysis.

\section{EXPERIMENTAL SECTION}

The climate of the Krasnoyarsk Territory is sharply continental: spring is long with sharp temperature fluctuations, summer is hot with sufficient moisture, autumn is short, winter is snowy and frosty.

The territory of the region is divided into two parts according to the type of relief. The western part is the eastern edge of the West Siberian Plain. It is a flathilly plain, where wide valleys of rivers alternate with watersheds. Above floodplain terraces of rivers have depressions, filled with upland bogs. The eastern part of the region is located on the Central Siberian Plateau. The relief is characterized by the presence of hills and deep valleys with steep slopes.

In the south of the region there are island foreststeppes. They are characterized by a flat and hilly terrain and fertile soils.

In the western part of the region dark coniferous forests predominate (spruce, fir, Siberian pine, Siberian larch). Larchpine and pine forests grow in the eastern part.

There are 5 types of soils on the territory of the region. They are divided in accordance with the load capacity. Rocky ground have the highest load capacity. They predominate in the eastern part of the region, in the Central Siberian Plateau. Clay is characterized by the lowest load capacity. It is predominantly present in the river valleys of the West Siberian Plain. Sandy soils prevail in the Lower Angara region. Also, rocky soil and gravel can be found in the region in small quantities.

As a result of the research, valuable theoretical and experimental data were obtained. The practical aspect of the study is presented below.

The development of a specialized GIAS for assessing the availability of wood resources, as well as planning and management of the logging process, involves the fulfillment of a number of tasks $[8,11]$ :

\section{Creating a database}

This is the most time consuming and informal part of the work. Its completeness and accuracy determine the quality of analysis and final products.

The first step in the creature of the GIAS project is the formation of database. Its basis is spatial data, along with their semantic environment. The GIAS provides a mechanism by which a digital model can be constructed from the spatial data of various sources [10].

When developing a digital database, the following steps are taken:

- database design. This definition of the boundaries of the terrain, coordinate system, necessary layers of data, objects in each layer, attributes, methods of coding and organization of attributes;

- input of the received data into the computer;

- digitizing or converting data from other formats;

- checking and correcting errors, creating topology;

- input of attributive data and connection of attributes with spatial objects;

- transformation of spatial data into real coordinates and joining of adjacent covers. For the development of the proposed GIAS, information is required on the exact boundaries of the forest areas, detailed information on transport routes, data on water bodies, data on tenants of forest areas, terrain data, information on wood growing stock, allowable cut volume and volumes of harvested wood, information on fire hazardous areas and water protection zones.

This information can be obtained from stateaffiliated organizations, research institutes, and industrial enterprises or on public Internet site. Information is processed on the ArcGIS platform.

\section{Analysis of data}

As a result of the GIAS analysis of the territory, a series of thematic maps, graphs and tables are produced as the output data. This information is visualized and therefore is available for understanding. For this reason, special attention should be paid to the presentation of information. Maps can be presented as 2D or 3D and give information about some terrain and site characteristics or analysis of different indicators. Also, the maps can be static or animated. For GIAS analysis of the territory, geostatistical analysis methods based on interpolation, extrapolation and approximation of data and various cartographic image methods based on data classification are used. Based on various factors, it is possible to carry out a comprehensive assessment of the territory for its 
suitability for the assigned tasks, as well as to conduct its zoning, ranking and clustering. Evaluation of the dynamics of the development of a phenomenon or process, as well as its prediction, can be modeled on the basis of different time data.

\section{Presentation of the analysis results}

The GIAS developed will allow the end user to specify the input parameters and obtain the required thematic maps by means of the Internet. In this case, the user does not need to have the skills to work in the ArcGISforDesktop software and understand the logic of the program, and highquality visualization of output data (maps) will allow using this product to a wide circle of users.

\section{RESULTS}

The presented method is tested in the Krasnoyarsk Territory in the Russian Federation. Based on the data of the Forestry Regulations of the Krasnoyarsk Territory forestry areas and free data from the wms-server of Rosreestr, a polygonal cartographic layer containing information on the exact boundaries of the forest districts of the Krasnoyarsk Territory was developed. The attribute table of this layer contains information for each forestry area: "allowable cut", "actually harvested wood" and "undeveloped resources".

For realization of this project, roads were digitized (including logging roads, highways, branches and temporary roads, railways, platforms and dead ends). Digitization was carried out on the basis of satellite images and displayed on the computer desktop. This information allows you to determine the transport availability of forest areas (Fig. 1).

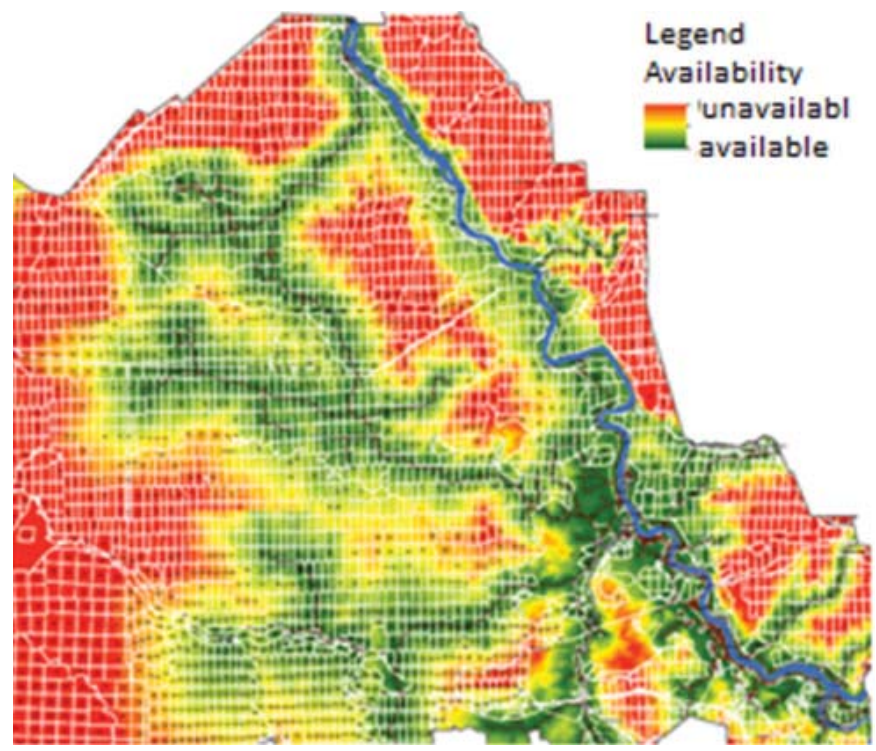

Figure 1: Image of transport availability of wood with overlap on a quarterly net

Information on topography is necessary for planning the development of the logging site. For the development of this layer, free data from the SRTM mission (Shut- tle radar topographic mission) is used this is a radar topographic survey covering a large part of the Earth's territory. The SRTM data for the territory of interest can be downloaded from the official site. Similarly, other archives are identified and downloaded for the area studied. Further, from the downloaded rasters, a common mosaic of rasters is formed.

After processing the obtained SRTM data, a raster layer is obtained with visual data on the angles in degrees divided into three categories in accordance with the availability of different technical means (Fig. 2).

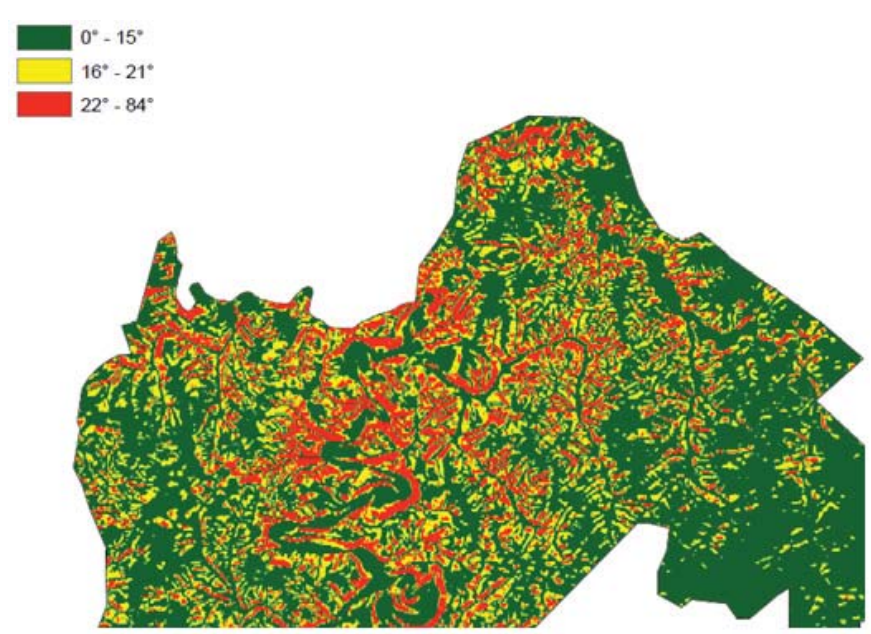

Figure 2: Distribution of the forest area according to the slope of the terrain

The map shows which slope prevails in a certain area. By imposing information about the upcoming logging (the borders of the cutting area, the planned transport routes on it, technical and technological availability is assessed by a slope.

It is convenient to use maps with relief shading (shadow modeling) to assess the technological availability, planning of development of cutting areas, determining the direction of cutting, skidding and removal, and also to determine the most convenient location of loading and landing points (Fig. 3).

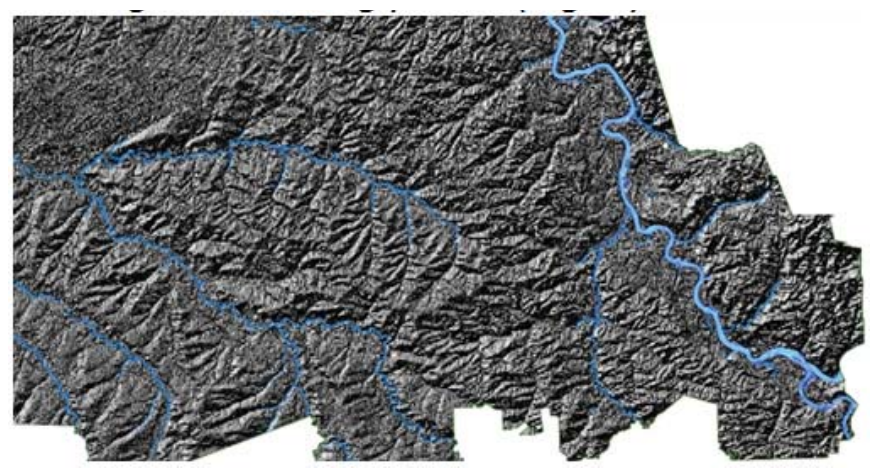

Figure 3: Terrain map with relief shading

As a result of the processing of water bodies, a layer of polygonal Water Protection Zone objects is obtained. Using the information of this layer, it is possible to assess the ecological availability of wood resources (it is pos- 
sible to identify illegal logging and identify those areas where cutting of wood is forbidden).

Then, the areas leased by enterprises are digitized. The attribute table contains information about the tenant, the lease contract number, and the date of the lease termination. So, you can get information about unoccupied plots.

On the basis of free data on soil resources, a soil map of forest areas was created [10]. According to the information received, it is possible to determine the technical and transport availability of wood. On the basis of the received map it is possible to plan transport ways, seasonality of transport of wood, types of forest machines.

This information can be provided to the user in a digital form, in the form of highresolution maps (more than 40,000 to 20,000 pixels) or in the form of thematic atlases that are easy to view and do not require additional software.

The layers of the GIAS take into account the influence of all factors that determine the level of availability of wood resources. To determine the influence of factors, the method of peer review was used. In this case, several layers are intended to reflect one factor.

Using this information, a forest user can evaluate various types of availability of forest resources on a leased forest site in a timely manner, as well as solve the problems of selecting forest plots for future lease, delivery of raw materials and availability of information on forest resources.
The completeness and detail of the assessment will allow to increase the efficiency of wood resources use, to select the optimal technology and machine system, to avoid environmental disturbance, to develop an optimal route for wood transportation. This will allow the forest user to make the maximum profit from the received timber products.

The obtained results of the assessment of the availability of wood resources, using the developed program in the Krasnoyarsk Territory are presented in Table 1 and in Figure 4. Data on the area of forests and timber reserves are obtained from the State Forest Register dated 01.07.2014 (in respect of forests located within the boundaries of the Krasnoyarsk Territory).

As the initial data necessary for the functioning of the developed GIAS, the most typical conditions for enterprises of the Krasnoyarsk Territory are accepted:

- manufactured products - saw logs;

- logging technology: Scandinavian (harvester + forwarder) and Canadian (cutting and milling machine + skidder + delimbers);

- transporting products: motor roads (KamAZ, MAN and Iveco trucks), waterways (if available). The territory within a radius of 10 kilometers from the existing logging roads is considered to be transport available (temporary forest roads can be laid).

Table 1: Results of assessing the availability of wood resources in the Krasnoyarsk Territory according to the developed geographic information and analytical system

\begin{tabular}{|c|c|c|c|}
\hline \multicolumn{2}{|c|}{ Index } & $\begin{array}{l}\text { Area of forest fund lands } \\
\text { cevered with forest vegetation } \\
\text { (thousand hectares) }\end{array}$ & $\begin{array}{l}\text { Wood growing stock } \\
\left(\text { million } \mathrm{m}^{3}\right)\end{array}$ \\
\hline \multicolumn{2}{|c|}{$\begin{array}{c}\text { Overall value of the indicator in the region, } \\
\text { including: }\end{array}$} & $105,054.1$ & $11,510.9$ \\
\hline \multirow{2}{*}{ Ecological availability } & Absolute value & $61,958.2$ & $7,709.7$ \\
\hline & $\%$ & 59.0 & 67.0 \\
\hline \multirow{2}{*}{ Technological availability } & Absolute value & $78,348.9$ & $9,154.9$ \\
\hline & $\%$ & 74.6 & 79.5 \\
\hline \multirow{2}{*}{ Technical availability } & Absolute value & $61,156.9$ & $7,061.6$ \\
\hline & $\%$ & 58.2 & 61.3 \\
\hline \multirow{2}{*}{ Transport availability } & Absolute value & $40,253.0$ & $5,367.0$ \\
\hline & $\%$ & 38.3 & 46.6 \\
\hline \multirow{2}{*}{ Economic availability } & Absolute value & $35,943.0$ & $4,755.5$ \\
\hline & $\%$ & 34.2 & 41.3 \\
\hline \multirow{2}{*}{$\begin{array}{l}\text { Total available wood } \\
\text { resources }\end{array}$} & Absolute value & $26,021.2$ & 3804.7 \\
\hline & $\%$ & 24.8 & 33.1 \\
\hline
\end{tabular}




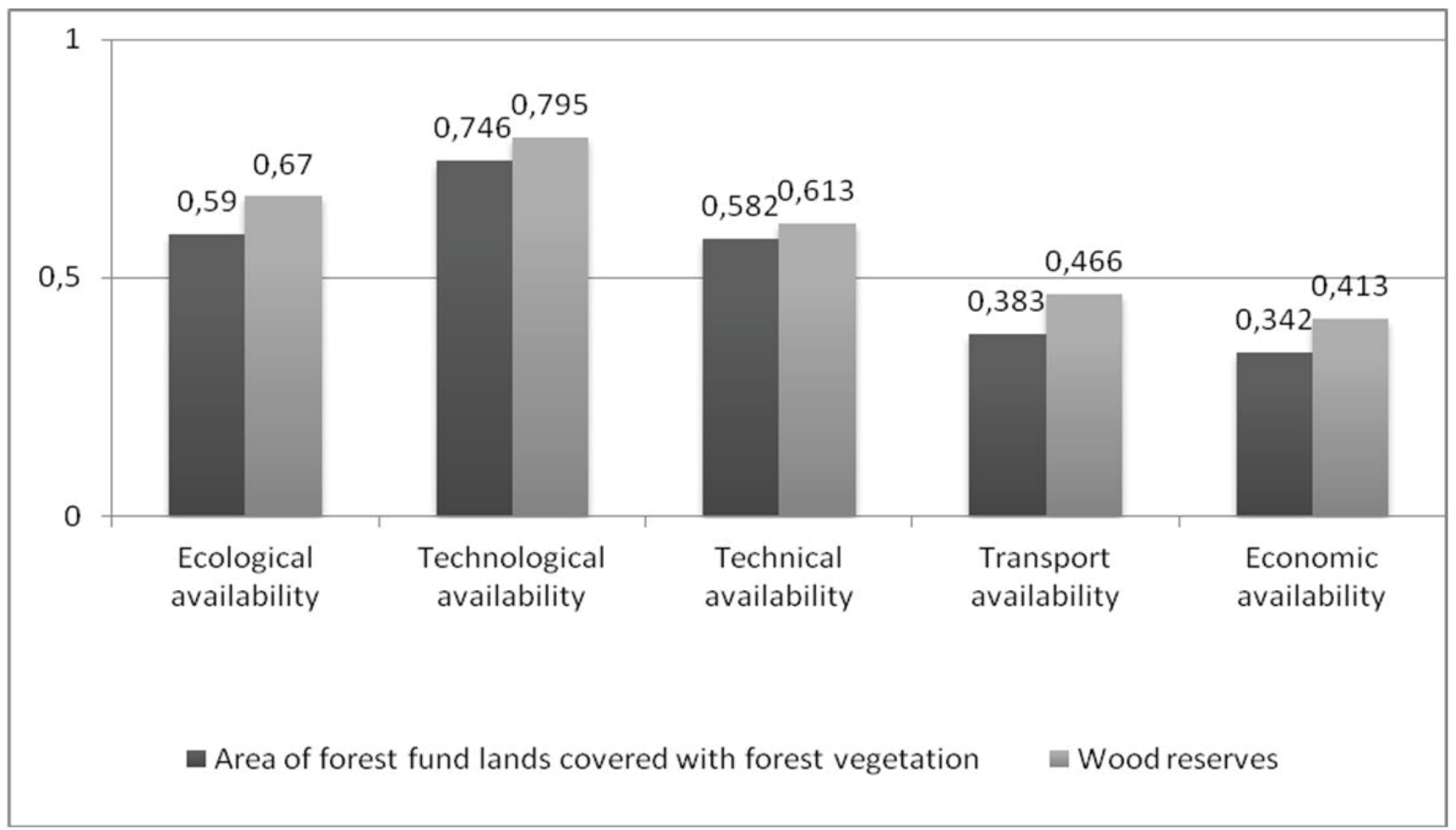

Figure 4: Diagram of availability of forest resources of the Krasnoyarsk Territory according to the developed geographic information and analytical system

The results obtained indicate that only $24.8 \%$ of the forest area and $33.1 \%$ of the timber stock in the Krasnoyarsk Territory can be considered available for effective development. At the same time, the lowest value is observed in the category of "economic availability" - 34.2\% and $41.3 \%$, respectively. This is due to the fact that the definition of economic availability, as already noted, focuses on all other types of availability. Consequently, only ecologically, technologically, technically and transport available wood resources can be economically available.

Based on the obtained assessment of the availability of forest resources in the Krasnoyarsk Territory, it can be concluded that it is generally low. To increase the efficiency of forest use in the region, it is necessary to search causes and factors that reduce the availability of forest resources, as well as the introduction of new methods and technologies in industrial processes.

Methods and technologies for increasing availability of wood resources should be discussed by all interested parties or experts of a specific forest cutting enterprise. Only with an integrated approach to this problem a really effective solution can be developed.

\section{ACKNOWLEDGEMENT}

The reported study was funded by RFBR according to the research project № 18-310-00311

\section{REFERENCES}

1. Tret'jakov A.G. 2015. Forest Rent and Economic Accessibility of Forest Resources: methodological aspects: Journal of the Moscow State Forest University - Forest Bulletin, № 2, p. 153.

2. Polshvedkin R.V., Mariev A.N. 2006. Assessment of the Availability and Quality of Forest Resources in the Udorsk Region of the Komi Republic. Methodological approach: Use of Geoinformation Systems in Environmental Management and Environmental Protection in the Republic of Komi: Materials of the scientific-practical conference].

3. Velazquez-Marti B., Annevelink E. 2009. GIS Application to Define Biomass Collection Points as Sources for Linear Programming of Delivery Networks: Transactions of the ASABE, № 52 (4), pp. 10691078.

4. Sokolov V.A. 2013. Organization of sustainable use of Siberian forests: Forest management information,. no 2. pp. 52-59.

5. Sokolov A. P., Syunev V. S., 2014. A toolset of decision support systems for wood harvesting and forest bioenergy logistics in Russia: Renewable energy sources and clean technologies: Proceedings of 14th international multidisciplinary scientific geoconference SGEM 2014. - Albena: STEF92 Technology. Vol.1. - pp. 3-10. 
6. Hashemkhani Z., S., Rezaeiniya, N., Zavadskas, K., E., Turskis, Z. 2011. Forest roads locating based on AHP and Coprasg methods: an empirical study based on Iran. E + M EKONOMIE A MANAGEMENT4: 6-21

7. Heinimann, H., R. 2017. Forest Road Network and Transportation Engineering-State and Perspectives. Croatian Journal of Forest Engineering 38(2) 155173.

8. Mokhirev A.P., Pozdnjakova M.O., Aksenov N.V. 2017. Comparative Analysis of the Availability of Forest Resources of Logging Enterprises: Engineering Bulletin of the Don, Vol. 44, № 1 (44). URL: http:// www.ivdon.ru/ru/magazine/archive/n1y2017/3954

9. Mokhirev A. P., Egarmin P. A. 2011. Geographic Information System for Planning Optimal Development of Forest Fund: Sistems. Methods. Technologies, № 4 (12), pp. 172-176. URL: http://www.brstu.ru/static/ unit/journal_smt/docs/number12/172-176.pdf
10. Mokhirev A.P., Goryaeva E.V., Egarmin P.A. 2017. Creation of a Geoinformation Resource for Logging Production Planning: Bulle-tin of SGUGiT (Siberian State University of Geosystems and Technologies), Vol. 22, № 2, pp. 137-153. URL: http://www.vestnik.ssga.ru/wp-con-tent/uploads $/ 2017 / 07 / \%$ D0\%A2\%D0\%BE\%D0\%BC-22$\%$ E2\%84\%96-2.pdf

11. Hosseini, S., A., Mazrae, M., R., Lotfalian, M., Parsakhoo, A. 2012. Designing an Optimal Forest Road Network by Consideration of Environmental Impacts in GIS. Journal of Environ-mental Engineering and Landscape Manage-ment, 20 (1): 58-66. 